\title{
EFFICACY OF QUADRATUS LUMBORUM BLOCKS IN ROBOTIC NEPHRECTOMY- A RETROSPECTIVE REVIEW.
}

Poonam Pai B.H ( $\sim$ poonampaibh@gmail.com )

Mount Sinai West-Morningside Hospital

Yan H. Lai

Mount Sinai West-Morningside Hospital

Abimbola Onayemi

Mount Sinai West-Morningside Hospital

Hung-Mo Lin

Mount Sinai West-Morningside Hospital

Research Article

Keywords:

Posted Date: July 13th, 2021

DOI: https://doi.org/10.21203/rs.3.rs-691058/v1

License: (c) (1) This work is licensed under a Creative Commons Attribution 4.0 International License.

Read Full License 


\section{Abstract}

Abstract: With the implementation of enhanced recovery pathways (ERAS) in kidney surgeries, regional techniques are being considered an important aspect of multimodal analgesia. Abdominal blocks such as quadratus lumborum block (QLB) have been used as an effective analgesic in abdominal surgeries, however their efficacy in kidney surgery remains unknown. To our best knowledge, there are no clinical studies exploring the relationship between QLBs and post-operative opioid consumption in robotic laparoscopic nephrectomy. Study Objectives: Assess analgesic efficacy between QLB and postoperative opioid consumption in robotic laparoscopic nephrectomy. Design and Setting: A retrospective chart review was conducted by querying the electronic medical record system of 2,200 bed tertiary academic hospital center in New York City. Outcomes: The primary measured outcome was postoperative morphine milli equivalent (MME) consumption for the first 24 hours. Secondary outcomes include intra-operative $\mathrm{MME}$, as well as postoperative pain scores measured on a visual analogue scale (VAS) scale at $2,6,12,18$, and 24 hours post-operatively. Results: The mean total post-operative MME in the pQLB group was $11[4,18]$ and $15[5.6,28]$ in the control group $(p=.001)$. There was a significant reduction in intra-operative MME in the QLB group in comparison to the control group. This reduction was not seen in post-operative MME. There was no significant difference in pain scores at any of the measured time points up to 24 hours post-operatively. Conclusion: Our study provides compelling support that ultrasound guided QLB significantly decreased intra operative opioid requirements but did not have the same effect on postoperative opioid requirements following robotic kidney surgeries in the context of an ERAS pathway. Keywords: Kidney surgeries, Robotic laparoscopic nephrectomy, quadratus lumborum block (QLB), enhanced recovery pathways (ERAS)

\section{Introduction:}

Approaches to contemporary urologic procedures range from open incisions to minimally invasive or robotically-guided techniques (1). Contributions to postoperative pain patients undergoing these surgeries may include the size of incision, location of port sites, pelvic organ nociception, discomfort due to urinary catheter, or diaphragmatic irritation from residual pneumoperitoneum $(2,3)$. Inadequately controlled postoperative pain may have harmful physiologic and psychological consequences that potentially increases perioperative morbidity and mortality $(4,5)$. Poor control of acute post-operative pain is associated with a higher incidence of progression to chronic pain (6). Excellent pain control is a cornerstone of enhanced recovery after surgery (ERAS) pathways, and specifically, multimodal analgesia after renal surgeries has yielded beneficial peri-operative outcomes such as improved functional recovery, reduced incidence of post-operative nausea and vomiting (PONV), mitigation of adverse effects of narcotics, all culminating in shorter hospital lengths of stay and increased patient satisfaction (7).

With varying success, regional anesthetic techniques such as neuraxial anesthesia, transverse abdominis plane (TAP) blocks and lumbar plexus blocks have been employed as part of ERAS protocols for renal surgeries. Similarly, systemic opioids, non-steroidal anti-inflammatory drugs (NSAIDS), magnesium and lidocaine have also been studied (8). The posterior quadratus lumborum block (pQLB) is an abdominal 
truncal block first described by Blanco in 2007 (9). He characterized it as an ultrasound (US) guided posterior TAP block (9). Anatomically, pQLB involves the injection of local anesthetic (LA) into a contiguous TAP interfascial plane that extends posteriorly to the thoracolumbar fascia (TLF) investing the quadratus lumborum muscle superiorly. The analgesic effect is produced by LA spread along these fascial planes targeting intercostal nerves that provide sensory innervation to the abdominal wall. Potential spreading patterns in cephalo-caudad as well as antero-posterior directions have been described, with potential involvement of paravertebral or neuraxial spaces (8).

Three types of QLB have been described and have anatomical names which describe the location of LA deposition around the QL muscle: QL1 or lateral, QL2 or posterior, and QL3 or transmuscular. Other modifications such as the paramedian sagittal oblique (PSO) and transverse oblique paramedian (TOP) orientations (10) also exist. These types of QLBs add complexity and diversity, but uncertainty to the efficacy of QLB in general. Based on the available literature on efficacy, ease of block placement, and complication profiles, we have adopted the PQLB as part of our ERAS protocol for robotic nephrectomies.

Previous studies have shown that the addition of PQLB to a regimen of morphine and NSAIDs to be associated with a significant reduction in opioid consumption in abdominal surgeries $(11,13)$. However, the efficacy of $\mathrm{PQLB}$ in renal surgeries remain unknown. To our best knowledge, there are no clinical studies exploring the relationship between PQLB and post-operative opioid consumption in robotic laparoscopic nephrectomy.

\section{Materials And Methods:}

Mount Sinai Institutional IRB approval for human subject research was obtained and a waiver for informed consent for retrospective chart reviewed was approved by IRB. All methods were performed in accordance with the relevant guidelines and regulations. We included all patients who underwent robotic and laparoscopic kidney surgeries between January 2015 and May 2018 a 2,200 bed academic medical center. The anesthesia information management system, Compurecord (Philips Medical, Andover, MA, USA), electronic medical record PRISM (GE, USA) and EPIC (Epic Systems Corporation, Verona, WI, USA) were queried. Intra operative opioid, post-operative opioid consumption, information about blocks performed and pain scores over the first postoperative 24 hours were collected.

All patients were monitored using standard ASA monitors and neuromuscular blockade was administered to facilitate endotracheal intubation after anesthetic induction. All anesthetics were maintained with inhaled agents. All patients received opioids intraoperatively at the discretion of the anesthesia practitioner depending on the intraoperative MAP and heart rate.

Patients were positioned in lateral decubitus position with operative side up. Posterior QLB were performed under direct visualization with an ultrasound machine (Sonosite Inc., Bothell, WA, USA) using a $13-6 \mathrm{MHz}$ broadband curvilinear probe. Blocks were performed by an attending anesthesiologist, or by a resident or a fellow under direct supervision, either prior to surgical incision or after the dressing was applied at the end of surgery. Blocks were placed with an insulated 22-gauge $50 \mathrm{~mm}$ block needle 
(Pajunk, Geisingen, Germany) inserted in an in-plane medial to lateral approach. After negative aspiration, 30 millimeters $(\mathrm{ml})$ of long acting LA $(0.25 \%$ bupivacaine or $0.2 \%$ ropivacaine) was injected in $5 \mathrm{~mL}$ aliquots, with direct visualization of spread in the intersection of pQLB and the TAP fascial planes.

Surgery was performed by two surgeons at the hospital locations, all specializing in robotic guided laparoscopic nephrectomies. We excluded open procedures or surgeries that were converted to open incisions. We also excluded patients who were administered patient-controlled analgesia (PCA) postoperatively or patients who received other forms of regional anesthetics.

The surgical incisions for robotic guided laparoscopic partial nephrectomy involved 3-4 keyhole incisions each measuring $1 \mathrm{~cm}$ in the abdomen. All patients were expected to remain in the hospital for 48 hours after surgery.

\section{Outcomes:}

The primary measured outcome was postoperative morphine milli equivalent (MME) consumption for the first 24 hours. Secondary outcomes include intra-operative MME, as well as postoperative pain scores measured on a VAS scale at 2, 6, 12, 18, and 24 hours post-operatively. Intra operative MME was calculated based on total intraoperative consumption of ketamine, remifentanil, fentanyl, hydromorphone and morphine. Post-operative MME was calculated based on total administration of fentanyl, hydromorphone, morphine and oxycodone. Peri-operative consumption of acetaminophen, gabapentin and ketorolac was also calculated.

Intraoperative maintenance anesthetic either volatile anesthetic or monitored anesthesia care after endotracheal intubation was recorded.

\section{Statistical Analysis:}

Descriptive data are reported as a number (\%), mean ( \pm standard deviation) or median (interquartile range [IQR]). For group comparisons, two-sample t-test or the Wilcoxon-Mann-Whitney tests was used for continuous data, and Chi-square or Fisher Exact test was used for categorical data, as appropriate. Linear regression models were built to compare the log-transformed intraoperative and postoperative MME use between the PQLB and control groups. Covariates such as age, gender, American Society of Anesthesiology (ASA) status, diabetes, hypertension, anesthesia team (resident or certified nurse anesthetist CRNA), anesthesia method (volatile anesthetic or total intravenous anesthesia TIVA), surgical duration and hospital site were adjusted between the two groups.

Logistic regression model using the generalized estimating equations method was used to compare the incidence of severe pain (pain score $\geq 7$ ) between the two groups during the first 24-hour period following surgery, and to test whether this incidence difference was the same over time. Odds ratios of reporting severe pain (visual analogue scale VAS of more than 7) at 2, 6, 12, 18 and 24 hours post operatively and 
the corresponding confidence intervals derived from the empirical standard errors were recorded. Analysis was performed using SAS 9.4 (SAS Institute Inc., Cary, NC). All tests were 2-sided and statistical significance was defined as a $p$ value $<0.05$, unless specified.

\section{Results:}

Out of the total 722 patients identified, 148 were excluded based on predetermined criterion. Two hundred eleven of the 554 patients who underwent laparoscopic/robotic assisted partial nephrectomies, received a pQLB as part of their analgesic strategy (Fig. 1).

Demographic data appear in Table 1. There was no significant difference between groups. Blocks were administered prior to surgical incision in $90.52 \%$ (191) and 9.48\% (20) after closure.

The median surgical duration was 136 [IQR 118, 161] minutes in the pQLB group and 151 [120, 182] minutes in the control group $(p=0.001)$. The median total intraoperative MME in the group receiving the pQLB was $10[3,25]$, compared to $55[40,85]$ in the group that did not receive the block $(p=0.001)$. Specifically, total intra-operative fentanyl administration was significantly reduced in the pQLB group $(p=$ 0.007). The mean total post-operative MME in the PQLB group was $11[4,18]$ and $15[5.6,28]$ in the control group $(p=.001)$ (Table 2$)$. After covariate adjustment between the two groups, the reduction in post-operative MME in the PQLB group was not significant.

The median pain scores at various time points(2,6,12,18,24hours) ranged from 2 [IQR $0-5]$ to 4 [IQR $0-6$ ] for the pQLB group, and 2 [IQR 0-5] to 3[IQR0-5] in the control group ( $\mathrm{p}$ value >0.05) (Table 3).

Additionally, there was a trend towards greater reduction of intraoperative MME when block was placed after surgery (Table 4). There was no significant difference in pain scores during the first 24 hours between the two groups. However, the odds of having severe pain tends to be consistently higher in the pQLB group (Table 5). 
Table 1

Demographic variables

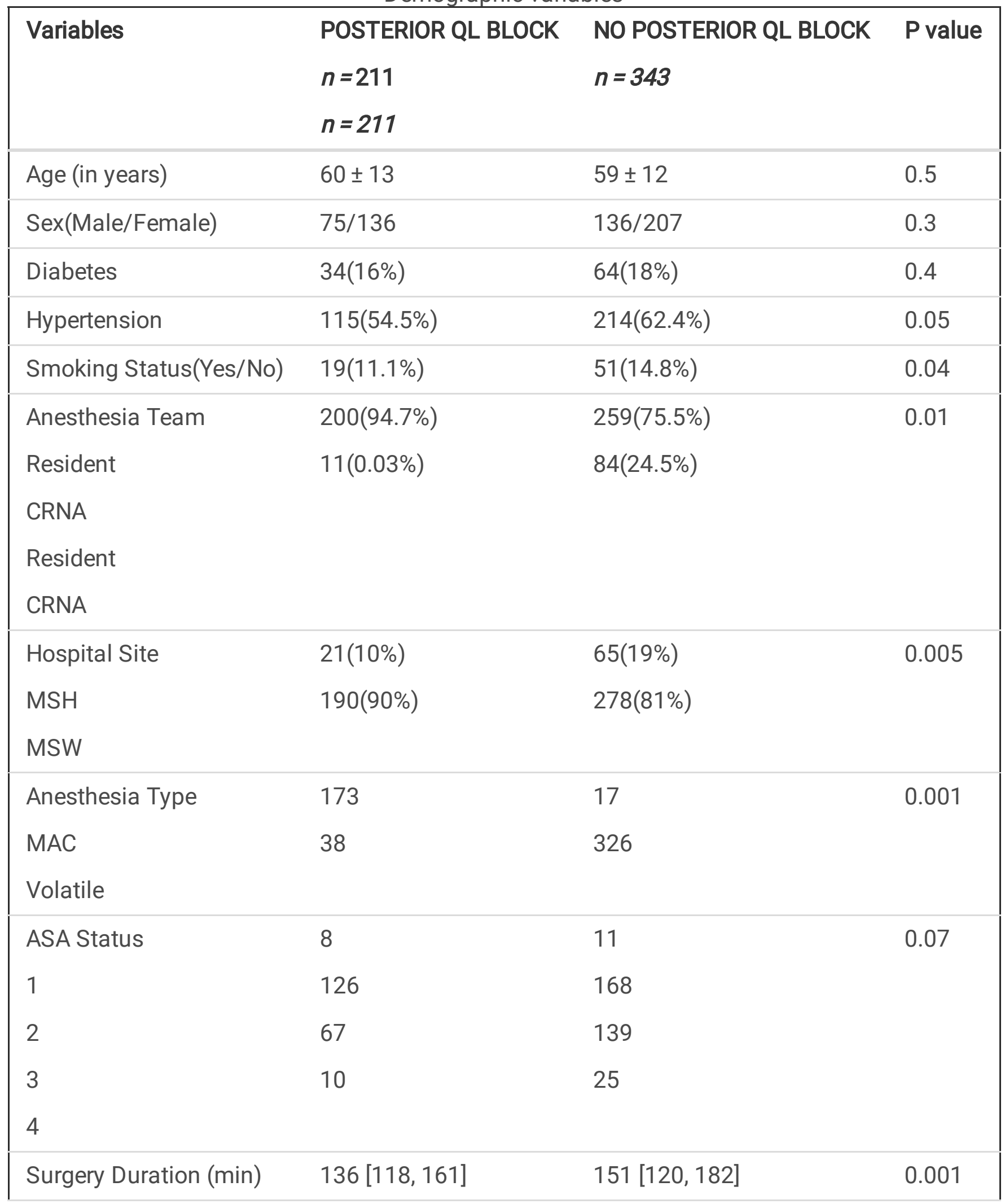




\begin{tabular}{|llll|}
\hline Variables & POSTERIOR QL BLOCK & NO POSTERIOR QL BLOCK & P value \\
& \multicolumn{1}{l}{$\boldsymbol{n}=\mathbf{2 1 1}$} & $\boldsymbol{n}=\mathbf{3 4 3}$ & \\
& $\boldsymbol{n}=\mathbf{2 1 1}$ & & 0.001 \\
\hline Type of surgery & $127(60 \%)$ & $233(68 \%)$ & \\
Laparoscopic & $84(40 \%)$ & $110(32 \%)$ & \\
Robotic & $121(57.3 \%)$ & $229(66.7 \%)$ & 0.001 \\
Partial & $90(42.6 \%)$ & $114(33.2 \%)$ & \\
Radical & & & 0.001 \\
\hline Block timing & $191(90 \%)$ & - & \\
Before Incision & $20(10 \%)$ & & \\
After Surgery & & & \\
\hline Local anesthesia & $202(95.8 \%)$ & & \\
Bupivacaine & $9(4.2 \%)$ & & \\
Ropivacaine & & & \\
\hline
\end{tabular}

Age, sex reported in mean and standard deviation. Surgery duration in median [IQR]. Categorical datadiabetes, hypertension, smoking status, anesthesia team, hospital site, anesthesia type, ASA status, type of surgery, block timing and local anesthesia reported in $\mathrm{n}$ percent. 
Table 2

Intra-operative and post-operative variables

\begin{tabular}{|c|c|c|c|c|c|}
\hline VARIABLES & \multicolumn{2}{|c|}{$\begin{array}{l}\text { POSTERIOR QL BLOCK } \\
n=\mathbf{2 1 1}\end{array}$} & \multicolumn{2}{|c|}{$\begin{array}{l}\text { NO POSTERIOR QL BLOCK } \\
n=343\end{array}$} & $P$ value \\
\hline Number of patients & MEDIAN[IQR] & $\begin{array}{l}\text { Number of } \\
\text { patients }\end{array}$ & MEDIAN[IQR) & & $\begin{array}{l}\text { Intra } \\
\text { operative } \\
\text { opioids: }\end{array}$ \\
\hline Ketamine (in mg) & 108 & $140[100,151]$ & 14 & $\begin{array}{l}124[88, \\
156]\end{array}$ & 0.3 \\
\hline $\begin{array}{l}\text { Remifentanil (in } \\
\mathrm{mg} \text { ) }\end{array}$ & 4 & $1.8[1.4,2.1]$ & 23 & $1.2[0.9,2.0]$ & 0.2 \\
\hline $\begin{array}{l}\text { Acetaminophen (in } \\
\mathrm{mg} \text { ) }\end{array}$ & 128 & $1000[1,000,1,000]$ & 109 & $\begin{array}{l}1000[1,000 \\
1,000]\end{array}$ & 0.4 \\
\hline Ketorolac (in mg) & 4 & $30[30,30]$ & 13 & $30[30,30]$ & 0.7 \\
\hline Fentanyl (in mcg) & 211 & $100[0,250]$ & 343 & $\begin{array}{l}500[300 \\
600]\end{array}$ & $<0.001$ \\
\hline $\begin{array}{l}\text { Hydromorphone (in } \\
\text { mg) }\end{array}$ & 211 & $0[0,0]$ & 343 & $0[0,1]$ & $<0.001$ \\
\hline Morphine (in mg) & 0 & $0[0,0]$ & 0 & $0[0,0]$ & 1 \\
\hline $\begin{array}{l}\text { Total Intra } \\
\text { operative MME }\end{array}$ & 211 & $10[3,25]$ & 343 & $55[40,85]$ & $<0.001$ \\
\hline \multicolumn{6}{|l|}{$\begin{array}{l}\text { Post-operative } \\
\text { opioids: }\end{array}$} \\
\hline $\begin{array}{l}\text { Acetaminophen (in } \\
\text { mg) }\end{array}$ & 26 & $1300[650,1300]$ & 65 & $\begin{array}{l}975[650 \\
1300]\end{array}$ & 0.35 \\
\hline Fentanyl (in mcg) & 117 & $100[75,100]$ & 192 & $\begin{array}{l}100[75 \\
150]\end{array}$ & 0.007 \\
\hline $\begin{array}{l}\text { Hydromorphone (in } \\
\text { mg) }\end{array}$ & 108 & $1[0.75,1.5]$ & 155 & $1.5[1,2.5]$ & 0.001 \\
\hline Oxycodone (in mg) & 134 & $12.5[10,30]$ & 200 & $20[10,30]$ & $<0.001$ \\
\hline Morphine (in mg) & 31 & $4[2,6]$ & 100 & $8[4,12]$ & $<0.001$ \\
\hline Gabapentin (in mg) & 3 & $300[100,800]$ & 6 & $\begin{array}{l}450[300 \\
600]\end{array}$ & 0.79 \\
\hline Ketorolac (in mg) & 12 & $53[30,60]$ & 39 & $60[45,90]$ & 0.10 \\
\hline $\begin{array}{l}\text { Total post- } \\
\text { operative MME }\end{array}$ & 211 & $11[4,18]$ & 343 & $15[5.6,28]$ & 0.001 \\
\hline
\end{tabular}

Intra operative and post-operative variables in number, median and interquartile range [IQR] with $p$ value. 
Table 3

Pain scores

\begin{tabular}{|llllllll|}
\hline $\begin{array}{l}\text { Time } \\
\text { Interval }\end{array}$ & \multicolumn{2}{l}{ POSTERIOR QL Block $(\boldsymbol{n}=\mathbf{2 1 1})$} & \multicolumn{2}{l}{ No POSTERIOR QL Block $(\boldsymbol{n}=343)$} & P \\
\cline { 2 - 7 } & Minimum & Maximum & Median[IQR] & Minimum & Maximum & Median[IQR] & \\
\hline Q2 & 0 & 10 & $4[0,6]$ & 0 & 10 & $3[0,5]$ & 0.06 \\
\hline Q6 & 0 & 10 & $2[0,5]$ & 0 & 10 & $3[0,5]$ & 0.21 \\
\hline Q12 & 0 & 10 & $2[0,5]$ & 0 & 10 & $3[0,5]$ & 1 \\
\hline Q18 & 0 & 10 & $3[0,5]$ & 0 & 10 & $3[0,5]$ & 0.64 \\
\hline Q24 & 0 & 10 & $3[0,5]$ & 0 & 10 & $2[0,5]$ & 0.07 \\
\hline
\end{tabular}

* Wilcoxon rank sum test

Pain scores at q2, q6, q12, q18 and q24 in medial and interquartile range [IQR] with $p$ value.

Table 4: Effect of QL block on MME during and after surgery.

\begin{tabular}{|c|c|c|c|c|c|c|}
\hline \multirow[t]{2}{*}{ Period } & \multirow[t]{2}{*}{$\begin{array}{l}\text { QL } \\
\text { block }\end{array}$} & \multirow[t]{2}{*}{ Variables } & $\begin{array}{l}\text { *Logarithmic scale } \\
\text { of MME }\end{array}$ & $\begin{array}{l}\text { Standard } \\
\text { Error }\end{array}$ & $\begin{array}{l}\mathrm{p}- \\
\text { value }\end{array}$ & $\begin{array}{l}\text { Overall p- } \\
\text { value }\end{array}$ \\
\hline & & & Difference & & & \\
\hline
\end{tabular}

\begin{tabular}{|c|c|c|c|c|c|c|}
\hline \multirow[t]{4}{*}{ Intraoperative } & Overall & Yes & -0.63 & 0.30 & 0.033 & 0.033 \\
\hline & & No & (ref) & & & \\
\hline & $\begin{array}{l}\text { Block } \\
\text { timing }\end{array}$ & $\begin{array}{l}\text { After } \\
\text { surgery }\end{array}$ & -1.02 & 0.50 & 0.042 & 0.065 \\
\hline & & $\begin{array}{l}\text { Before } \\
\text { incision }\end{array}$ & -0.54 & 0.31 & 0.079 & \\
\hline & & Not done & (ref) & & & \\
\hline \multirow[t]{5}{*}{ Postoperative } & Overall & Yes & -0.27 & 0.38 & 0.480 & 0.480 \\
\hline & & No & (ref) & & & \\
\hline & $\begin{array}{l}\text { Block } \\
\text { timing }\end{array}$ & $\begin{array}{l}\text { After } \\
\text { surgery }\end{array}$ & -0.85 & 0.64 & 0.184 & 0.411 \\
\hline & & $\begin{array}{l}\text { Before } \\
\text { incision }\end{array}$ & -0.14 & 0.39 & 0.727 & \\
\hline & & Not done & (ref) & & & \\
\hline
\end{tabular}

* Based on linear models adjusting for age, gender, diabetes, hypertension comorbidities, ASA status, anesthesia team, anesthesia method, surgical duration and hospital site. 
Table 5: Odds ratio of having severe pain for POSTERIOR QL block over time post-surgery

\begin{tabular}{llll}
$\begin{array}{l}\text { Time } \\
\text { Point }\end{array}$ & OR & $95 \% \mathrm{Cl}$ & p-value $^{*}$ \\
\hline $2 \mathrm{~h}$ & 1.52 & $(0.83,2.80)$ & 0.180 \\
\hline $6 \mathrm{~h}$ & 1.01 & $(0.54,1.91)$ & 0.965 \\
\hline $12 \mathrm{~h}$ & 1.27 & $(0.68,2.32)$ & 0.465 \\
\hline $18 \mathrm{~h}$ & 1.37 & $(0.79,2.69)$ & 0.236 \\
\hline $24 \mathrm{~h}$ & 1.92 & $(0.99,3.71)$ & 0.052
\end{tabular}

* $\mathrm{P}$-value $=0.391$ for the time ${ }^{\star} \mathrm{QL}$ interaction term. Odds ratios were adjusted for age, gender, diabetes, hypertension comorbidities, ASA status, anesthesia team, anesthesia method, surgical duration and hospital site.

\section{Discussion:}

This is a retrospective review of patients who underwent robotic and laparoscopic kidney surgeries. There was a significant reduction in intra-operative MME in the group of patients who received a PQLB in comparison to the control group. This reduction was not seen in post-operative MME, nor was there any significant difference in pain scores at any of the measured time points up to 24 hours postoperatively.

Managing postoperative pain in kidney surgeries presents a unique set of challenges. In our multimodal analgesic and ERAS pathways, avoidance of NSAIDs and opioids is prudent owing to concerns of nephrotoxicity with accumulation of active and nondialyzable metabolites (12). The possibility of impaired creatinine clearance must be considered when dosing other opiates as well. With the increasing numbers of kidney surgeries occurring worldwide, further exploration of modern analgesic techniques is timely (18).

Ultrasound guided regional anesthesia is highly beneficial after abdominal surgery. Truncal blocks such as TAP blocks have been performed in donor nephrectomies and was found to have reduced pain scores and reduced morphine consumption during the first 24 hours post-operatively $(14,15)$. Li et al performed a placebo controlled randomized control trial in partial and radical nephrectomy and found that preoperative TAP block was effective in reducing intra-operative and post-operative opioid consumption but had no effect on pain scores and length of stay (16). The PQLB, a variation of the posterior TAP block, is being studied extensively in abdominal surgeries. Blanco et al compared TAP blocks to pQLBs after caesarian section under spinal anesthesia. He concluded that PQLB significantly reduced the consumption of morphine after cesarean delivery in comparison to TAP blocks (17). 
However, the efficacy of pQLB in kidney surgeries remains heterogeneously ambiguous. Elsharkawy et al reported that the use of transmuscular QLB provided appropriate sensory blockade for open urological surgeries (18). Using a pQLB approach, Zhu et al concluded that patients in the pQLB group had lower sufentanil consumption in the first 24 hours after laparoscopic nephrectomy when compared to the control group (19). In contrast, Boulianne et al did not observe a reduction in postoperative opioid administration at 24 hours with a pQLB in patients undergoing elective colorectal surgery. Post-operative pain scores were actually lower in the control group (20).

Although QLBs are widely adopted into practice despite firm evidence on their efficacy, complications, and nerve targets or local anesthetic (LA) spreading patterns, there have been some mixed results regarding effectiveness of pQLB. Various authors conclude that it is important to consider the type of pQLB while interpreting study results. Kukreja et al demonstrated that the VAS pain score at 24 hours and cumulative opioid consumption were significantly lower in the anterior QLB group after total hip arthroplasty (THA) as compared with controls (21). Without a PQLB comparison group, Green et al suggested that the use of transmuscular QLB in patients undergoing THA shortened the length of stay to an average of 2.9 days in comparison to 5.1 days. The intraoperative fentanyl use was also considerably lower in the block group under general anesthesia (22). In major orthopedic procedures, Hebl et al., showed that ERAS programs utilizing peripheral nerve blocks had significant impacts on perioperative outcomes, such as shortened hospital length of stay and fewer adverse events such as ileus and urinary retention (23). Patients participating in ERAS pathways had lower post-operative pain scores, opioid requirements, and incidences of adverse effects.

The timing of the performance (pre or postoperatively) of the PQLB is an important factor that is rarely studied. The pre-incision PQLB timing in our study was not associated with reduction of total MME for both the intra-operative and post-operative periods, with the odds ratio of having lower pain scores if the block was performed after the conclusion of surgery. Surgical incision triggers an inflammatory reaction to damaged tissues that induces central sensitization of pain pathways. It has been proposed that antinociceptive protection provided by pre-emptive treatments should extend into the postoperative period to effectively cover the inflammatory phase. In turn, pre-emptive analgesia focuses on minimizing central sensitization and potentially decreasing the incidence of developing chronic neuropathic pain. (24) Similar to our study, Olanipekun et al conducted a study comparing pre incisional and post incisional ilioinguinal and iliohypogastric nerve block to control post-operative pain in children after herniotomy.

They concluded that though the mean pain scores were lower in the pre-incision group at 6 hours, they were higher at 24 hours in comparison to the post-operative block group. (25)

Our study has limitations that are inherent to a retrospective study. Anesthetic practices and regional anesthetic techniques were not controlled nor standardized, thus the true efficacy and effectiveness of pQLB could be underreported. Randomized controlled trials assessing the efficacy should focus on standardization of techniques including the types of QLB utilized. The size of our surgical cohort was sufficient to demonstrate statistical significance. Despite PQLB being performed in patients under general 
anesthesia, because patients, surgeons, anesthesiologists, nor perioperative personnel were not blinded from the techniques, placebo effects might have influenced the narcotic demands in the PQLB group, and nonblinded practitioners could introduce further bias.

In conclusion, our study provides compelling support that ultrasound guided pQLB significantly decreased intra operative opioid requirements but did not have the same effect on postoperative opioid requirements following robotic kidney surgeries in the context of an ERAS pathway.

\section{Declarations}

Acknowledgements:

Garrett Burnett, MD, and Wayne Sy MD for helping with the data collection.

Declaration of Interests: There is no material benefit expected from publication of this work. The study sponsor did not have a role in the study design, collection, analysis, interpretation of the data, writing of the report or decision to submit the report for publication. This declaration applies the same to all authors listed.

\section{Conflicts of declaration: None}

\section{Funding: None}

Detail of Author contributions:

PP: Primary investigator responsible for study design and planning, IRB approval, data collection, subject recruitment, manuscript writing and preparation, data analysis, safety monitoring and responding to adverse events/outcomes.

AO: Research assistant involved in data collection.

HML: Primary statistician involved in data analysis, manuscript editing.

YL: Primary investigator responsible for study design and planning, data collection, subject recruitment, manuscript writing and preparation, data analysis, safety monitoring and responding to adverse events/outcomes.

\section{References}

1. Frampton, S. \& Kneebone, R. L. John Wickham's New Surgery: 'Minimally Invasive Therapy', Innovation, and Approaches to Medical Practice in Twentieth-century Britain. Soc Hist Med, $\mathbf{3 0}$ (3), 544-566 https://doi.org/10.1093/shm/hkw074 (2017).

2. Hager, B. et al. Comparison of early postoperative pain after partial tumour nephrectomy by flank, transabdominal or laparoscopic access. Br J Pain, 13 (3), 177-184 
https://doi.org/10.1177/2049463718808542 (2019).

3. Mathuram Thiyagarajan, U., Bagul, A. \& Nicholson, M. L. Pain management in laparoscopic donor nephrectomy: a review. Pain Res Treat, 2012, 201852 https://doi.org/10.1155/2012/201852 (2012).

4. Gan, T. J. Poorly controlled postoperative pain: prevalence, consequences, and prevention. J Pain Res, 10, 2287-2298 Published 2017 Sep 25https://doi.org/10.2147/JPR.S144066 (2017).

5. Joshi, G. P. Multimodal analgesia techniques and postoperative rehabilitation. Anesthesiology Clinics of North America, 23 (1), 185-202 (2005).

6. Katz, J., Jackson, M., Kavanagh, B. P. \& Sandler, A. N. Acute pain after thoracic surgery predicts longterm post-thoracotomy pain. Clin J Pain. 1996 Mar;12(1):50 - 5. doi: 10.1097/00002508-19960300000009. PMID: 8722735.

7. Prasad, S. E., Vasdev, V. \& Mohan, N. -S G. Post-Operative Pain Management in Patients Undergoing Robotic Urological Surgery. Curr Urol 2016 Feb;9(1):5-11. doi: 10.1159/000442843. Epub 2016 Feb 10. PMID: 26989364; PMCID: PMC4789944.

8. Gelman, D. et al. Role of Multimodal Analgesia in the Evolving Enhanced Recovery after Surgery Pathways. Medicina (Kaunas). 2018;54(2):20. Published 2018 Apr 23. doi:10.3390/medicina54020020.

9. Abrahams, M., Derby, R. \& Horn, J. L. Update on Ultrasound for Truncal Blocks: A Review of the Evidence. Reg Anesth Pain Med. 2016 Mar-Apr;41(2):275 - 88. doi:

10.1097/AAP.0000000000000372. PMID: 26866299.

10. Balocco, A. L. et al. Quadratus lumborum block: an imaging study of three approaches. Reg Anesth Pain Med, 46, 35-40 https://doi.org/10.1136/rapm-2020-101554 (2021).

11. Ueshima, H., Otake, H. \& Lin, J. Ultrasound-Guided Quadratus Lumborum Block: An Updated Review of Anatomy and Techniques. Biomed Res Int. 2017; 2017:2752876. PMID: 28154824.

12. Akerman, M., Pejčić, N. \& Veličković, I. A Review of the Quadratus Lumborum Block and ERAS. Front Med (Lausanne), 5, 44 Published 2018 Feb 26https://doi.org/10.3389/fmed.2018.00044 (2018).

13. Blanco, R., Ansari, T. \& Girgis, E. Quadratus lumborum block for postoperative pain after caesarean section: A randomized controlled trial. Eur J Anaesthesiol. 2015 Nov;32(11):812-8. doi: 10.1097/EJA.0000000000000299. PMID: 26225500.

14. Gopwani, S. R. \& Rosenblatt, M. A. Transversus abdominis plane block in renal allotransplant recipients: A retrospective chart review. Saudi J Anaesth, 10 (4), 375-378 https://doi.org/10.4103/1658-354X.177326 (2016).

15. Aniskevich, S. et al. Ultrasound-guided transversus abdominis plane blocks for patients undergoing laparoscopic hand-assisted nephrectomy: a randomized, placebo-controlled trial. Local Reg Anesth, 7, 11-16 Published 2014 May 25https://doi.org/10.2147/LRA.S61589 (2014).

16. Li, X. et al. The analgesic efficacy of ultrasound-guided transversus abdominis plane block for retroperitoneoscopic renal surgery: a randomized controlled study. BMC Anesthesiol, 19, 186 https://doi.org/10.1186/s12871-019-0850-3 (2019). 
17. Blanco, R., Ansari, T., Riad, W. \& Shetty, N. Quadratus Lumborum Block Versus Transversus Abdominis Plane Block for Postoperative Pain After Cesarean Delivery: A Randomized Controlled Trial. Regional Anesthesia and Pain Medicine, 41 (6), 757-762 (2016).

18. Elsharkawy, H., Ahuja, S., DeGrande, S., Maheshwari, K., Chan, V. \& \& \& \& Subcostal approach to anterior quadratus lumborum block for pain control following open urological procedures. Journal of Anesthesia, 33, https://doi.org/10.1007/s00540-018-02605-1 (2019).

19. Zhu, M. et al. Analgesic effect of the ultrasound-guided subcostal approach to trans muscular quadratus lumborum block in patients undergoing laparoscopic nephrectomy: a randomized controlled trial. BMC Anesthesiol, 19, 154 https://doi.org/10.1186/s12871-019-0825-4 (2019).

20. Boulianne, M. et al. Effects of quadratus lumborum block regional anesthesia on postoperative pain after colorectal resection: a randomized controlled trial. Surg Endosc. 2020 Sep;34(9) 4157-4165. doi:10.1007/s00464-019-07184-0. PMID: 31641913.

21. Kukreja, P. et al. Anterior quadratus lumborum block analgesia for total hip arthroplasty: a randomized, controlled study [published online ahead of print, 2019 Oct 25]. Reg Anesth Pain Med, https://doi.org/10.1136/rapm-2019-100804 (2019). rapm-2019-100804

22. Stuart Green, M., Ryan Hoffman, C., Iqbal, U., Olabisi Ives, O. \& Hurd, B. Trans muscular Quadratus Lumborum Block Reduces Length of Stay in Patients Receiving Total Hip Arthroplasty. Anesth Pain Med, 8 (6), e80233 Published 2018 Nov 20https://doi.org/10.5812/aapm.80233 (2018).

23. Hebl, J. et al. \& \& \& \& \& \& (2008). A Pre-Emptive Multimodal. Pathway Featuring Peripheral Nerve Block Improves Perioperative Outcomes After Major Orthopedic Surgery. Regional anesthesia and pain medicine. 33.510-7. 10.1016/j.rapm.2008.04.008.

24. Price, T. J. \& Inyang, K. E. Progress in Molecular Biology and Translational Science. Volume 131.Elsevier; Amsterdam, The Netherlands: 2015. Commonalities between pain and memory mechanisms and their meaning for understanding chronic pain;pp. 409-434.

25. Olanipekun, S. O., Adekola, O. O., Desalu, I. \& Kushimo, O. T. The Effect of Pre-Incision Field Block versus Post-Incision Inguinal Wound Infiltration on Postoperative Pain after Paediatric Herniotomy. Open Access Maced J Med Sci. 2015 Dec 15;3(4):666 - 71. doi: 10.3889/oamjms.2015.116. Epub 2015 Nov 14. PMID: 27275305; PMCID: PMC4877905.

\section{Figures}




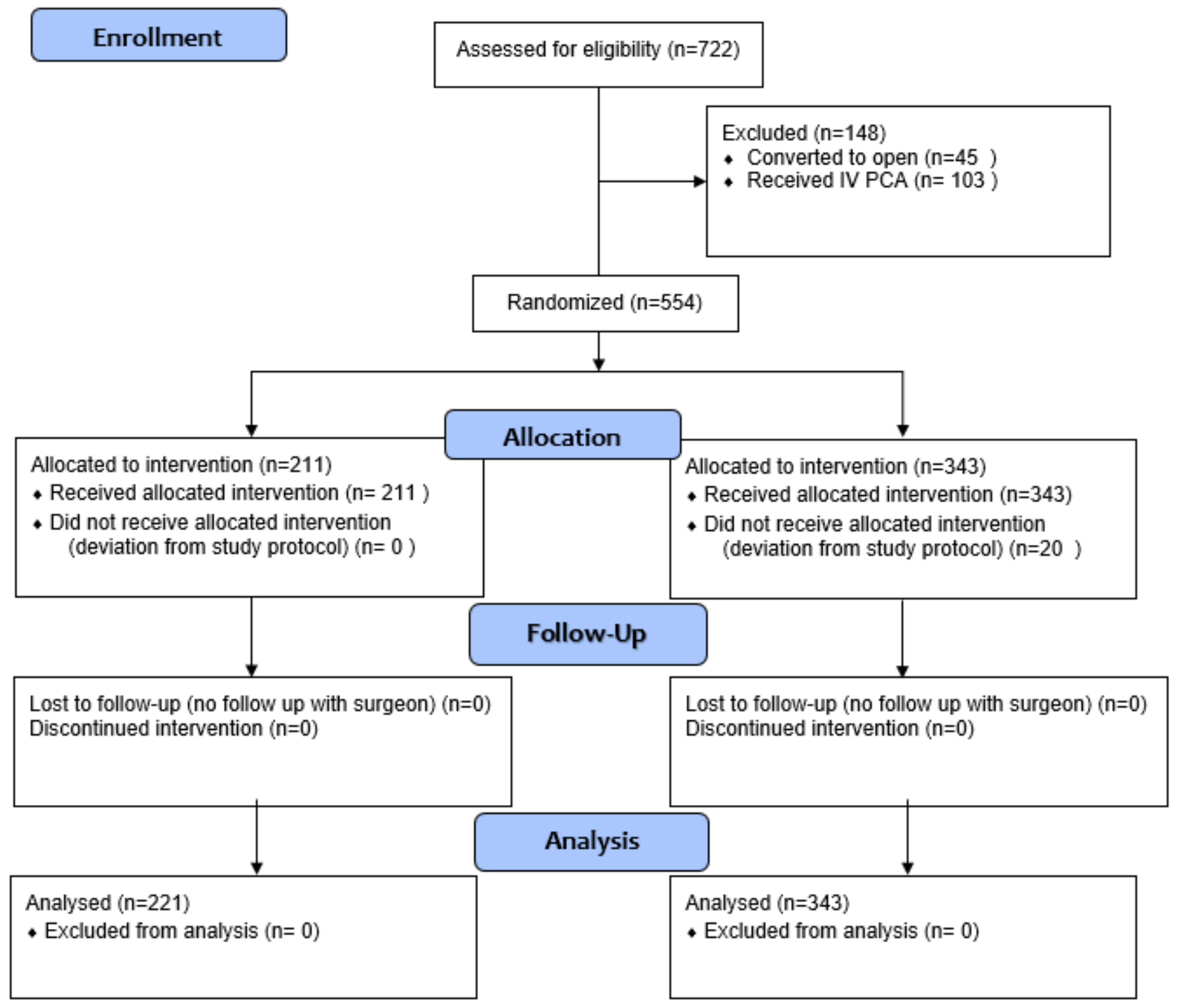

Figure 1

FLOW DIAGRAM 